\title{
O EXTRAORDINÁRIO E HESITANTE CAMINHO DA LIBERDADE O DIA DOS PRODÍGIOS DE LÍDIA JORGE
}

\author{
Edvaldo A. Bergamo*
}

O romance português pós- 25 de Abril focaliza tematicamente de maneira recorrente e com estratégias formais diversificadas um impasse histórico que se estendeu por boa parte do século xx: a interferência da prolongada ditadura salazarista na vida econômica, política e cultural da sociedade lusitana. A configuração romanesca mira tal cenário histórico persistente com o objetivo de representar o processo de desagregação social orquestrado por um regime autoritário caracterizado pela violência e pela repressão. Para os estudiosos do assunto, como Jaime Ginsburg e Rosani Umbach, o autoritarismo

[...] consiste em uma caracterização de um regime político em que existe um controle da sociedade por parte do Estado, que manipula as formas de participação política e restringe a possibilidade de mobilização social; existe interesse político na cooptação dos intelectuais; a administração pública é apresentada como um bem em si mesmo, ao servir ao interesse do Estado; o setor militar desempenha um papel decisivo na manutenção da ordem. Nas formas extremas, como o totalitarismo, o regime autoritário institui um partido único e reprime com rigor manifestações de contrariedade.

$[\ldots]$

O fato de o Estado agir de maneira a controlar as ações individuais, restringir as possibilidades de mudança social, sustentar códigos e valores com os quais a população é obrigada a pautar sua existência, e manipular a difusão de ideologias em favor da conservação do poder das elites, estabelece uma condição restritiva de existência. O problema da reificação, desenvolvida dentro do capitalismo industrial, é levado a dimensões novas, agravadas pela ameaça de destruição coletiva. (GNZBURG \& UMBACH, 2000: p. 238).

No tocante a uma literatura de intervenção social, oriunda de uma conjuntura que concerta literatura, história e política, o grande momento, certamente, foi a década de 1930, na qual de modo notório o empenho ideológico tomou um grande vulto nas manifestações artísticas de língua portuguesa. $\mathrm{O}$ engajamento

"Licenciado, Mestre e Doutor em Letras pela UNESP, campus de Assis/SP. Atualmente, é docente da Universidade de Brasília (UnB), onde desenvolve pesquisa e orienta alunos de Graduação e Pós-Graduação na área de Literatura e Autoritarismo. 
literário tornou-se um fenômeno supranacional nos países de língua portuguesa, atuando em favor das reivindicações sociais vigentes, através de uma perspectiva que conciliava literatura e empenho político. $\mathrm{O}$ interesse pela representação das tensões sociais em voga é a tônica dessa literatura, definida por meio de um alargamento de perspectivas, principalmente na tentativa de retratar o quadro geral de uma sociedade em transformação por um processo de modernização desigual, inconcluso e autoritário. Ao aproveitar o legado do realismo crítico proveniente do século XIX, as literaturas de língua portuguesa reinterpretaram esse realismo sob a ótica dos novos conflitos sociais e agravados, ainda mais, em países periféricos como Portugal, que sofria com um regime totalitário que se prolongaria por muitos anos. Autoproclamando-se militantes, os autores lutavam pelos seus ideais utópicos, procurando afirmar literariamente suas convicções com reflexos inclusive na reformulação do projeto de uma identidade nacional desapegado de idealismo ingênuo. Nos textos engajados do período, percebe-se o peso da ideologia dos escritores, uma vez que eram intelectuais conscientes de sua missão como intérpretes da realidade observada em sentido histórico, político e social.

A hipótese ventilada aqui é que o escopo artístico dos anos de 1930 do século xx de revalorização do realismo e de aprofundamento da questão social deixou marcas que foram aproveitadas e/ou reformuladas por tendências literárias posteriores. Na segunda metade do século Xx, certamente, o desenvolvimento cultural abriu outras fronteiras de atuação e inovadoras trilhas de expansão para a literatura e a arte em geral. O romance, nessa ulterior conjuntura, continua sendo um dos principais gêneros literários da atualidade, revigorado por aspectos diversos. No plano temático, aparecem com destaque a reavaliação da História, a representação das minorias raciais e sexuais e o enfoque nos problemas dos povos pós-coloniais. No plano formal, preponderam as estratégias narrativas que utilizam como recursos dominantes a intertextualidade, a autorreferencialidade e a autorreflexividade.

Diante da diversidade vigorosa do gênero romanesco e da existência de inúmeros problemas concernentes à realidade histórica da segunda metade do século xx, é precipitado sugerir o esgotamento do projeto estético-ideológico de uma literatura de ênfase social. Seria mais produtivo, em termos críticos, cogitar em um possível desdobramento e em uma reformulação de um empreendimento artístico, hipoteticamente procedente da década de 1930, que vem atender às renovadas demandas prementes da segunda metade do século xx, marcada contextualmente pela continuidade da ditadura salazarista em Portugal, para ficarmos apenas com a complexa relação literatura e autoritarismo.

Carlos Reis (2005) afirma que o romance português pós-25 de Abril caracteriza-se por três decisivas tendências: o romance de revisão da História, o romance de autoria e temática feminina e o romance sobre a guerra colonial. O romance de Lídia Jorge perpassa basicamente as três tendências da ficção portuguesa pós-25 de Abril: apresenta uma nítida consciência histórica, privilegia o univer- 
so feminino e, ainda, não ignora o ultracolonialismo português em África. Vale ressaltar que o tema da condição feminina atravessa majoritariamente a obra da autora em questão, modelando questões políticas e históricas, sob a perspectiva predominante da mulher.

Especificamente no seu primeiro romance, O Dia dos Prodígios (1980), é narrado um episódio aparentemente insólito que afeta a vida de todos os habitantes de um lugarejo, no Algarve, denominado Vilamaninhos. Entre acontecimentos reais e imaginários, o ambiente pacato do povoado é perturbado por um evento inusitado: o aparecimento de uma cobra voadora, cena narrativa nuclear que funciona como uma peça-chave do relato e mote aglutinador dos fragmentos narrativos focados em determinados habitantes da cidadezinha, notadamente do sexo feminino. De modo geral, o destaque está no retrato do marasmo e do despreparo de uma pequena aldeia algarvia para as alterações radicais vindouras, as quais todos os moradores do povoado tentam perceber/captar de alguma maneira, seja pela via intelecto-racional, seja pela via mítico-alegórica, majoritariamente.

$\mathrm{O}$ recurso à multiplicidade de vozes em perspectiva engendra uma narrativa configurada como um mosaico de pequenos relatos acerca da vida de personagens oprimidas, cujos pontos de vista são valorizados no andamento do relato, no que toca à interferência do episódio da cobra voadora no mundo apagado de indivíduos silenciados pela violência, pela loucura, pelo preconceito, pela intolerância, pelo abandono. A cena inusitada da cobra voadora, fenômeno cuja ambiguidade não deixa indiferentes os habitantes do lugarejo, é o episódio que mobiliza a intriga/fábula, construída fragmentariamente com base em seres relegados que têm suas vidas transformadas pelo insólito acontecimento, com destaque, vale ressaltar, para o elemento feminino, marginalizado historicamente, como agente catalisador das mudanças que abalam os moradores de uma cidadezinha afastada dos centros de decisão política e econômica e desconhecedora dos movimentos subterrâneos que preparavam a abrupta transformação da ordem social e política com um golpe de estado, protagonizado por militares (mais uma ironia da História?), que derrubaria uma ditadura de muitas décadas. A grande metáfora do romance é a da eterna espera sebastianista de um povo que, ilhado em sua insignificância, já não percebe ou compreende os sinais preconizadores de mudança, quando de fato aparecem. Ironicamente, o romance dá destaque a um coletivo que aguarda e não reconhece os verdadeiros acontecimentos prodigiosos. A demora de um milagre sempre desejado metamorfoseia-se em descrença e desconfiança para uma gente que cansou de ter esperança e acredita mais numa cobra que voa do que em movimentos revolucionários.

No romance em questão a construção das personagens (CANDIDO, 1974) e a configuração do espaço (LiNs, 1976) apresentam uma inegável conotação estético-ideológica que orienta o andamento da narrativa e direciona a visão de mundo adotada pelo relato. 
Habitantes de um lugarejo abandonado que aguarda por algo extraordinário, em O Dia dos Prodígios, destacam-se as oprimidas personagens femininas como agentes que, na dianteira, ativam os sinais de mudanças que interferem na vida cotidiana de um vilarejo esquecido. As personagens com maior desenvoltura na trama são as duas Carminhas (Carminha Rosa e Carminha Parda), Jesuína Palha, Esperança Teresa e Branca Volante. As Carminhas estão reclusas dentro da sua própria casa para se defenderem da hostilidade moral do vilarejo, Jesuína Palha é a anunciadora do espetáculo miraculoso da cobra voadora e uma espécie de matriarca ancestral defensora de uma moral rígida, Esperança Teresa é a vítima exemplar de um casamento infeliz e Branca Volante, oprimida igualmente por um casamento brutal, desenvolve o dom da clarividência que possibilita o exercício da autoconsciência como encorajamento à mudança ou à inevitável transformação vindoura. Apenas uma passagem do romance é suficiente para demonstrar o destaque recebido pelas personagens femininas, em vista das conotações políticas e culturais que encerram na citada obra:

Ainda ontem Pássaro procurava a mulher na cama, e ela vá de fazer de morta. Então ele de levantar a mão para lhe chimpar a cara. Porque com as bestas, um homem dá aveia e elas comem, mas se lhes der só palha acabam por comê-la e ainda por suspirar pelo dono quando lhe pressentem os passos. Suspiram e regougam. Não guardam rancor. Às vezes dá-se-lhe na pele, e elas apenas encolhem o lombo. Quanto muito um pinote. Voltando a dar cevada e aveia, elas riem logo a um homem. De orelha estendida. Menos a mula Menina, que se foi. Mas com as pessoas é diferente. Porque cada bocadinho que lhes tires uma vez, nem mais por isso, as poderás compensar. Embora as pessoas possam disfarçar as mágoas. (JORGE, 1980: p. 107)

Em consonância com outros aspectos da narrativa, a configuração do espaço, no mencionado romance, apresenta uma incontornável nota ideológica que indicia enclausuramento, exclusão e opressão. Em O Dia dos Prodígios, o espaço principal é a praça da pequena cidade, onde acontece grande parte das ações diretamente vinculadas ao episódio insólito propulsor da narrativa, a visão/testemunho da cobra voadora, e as consequentes especulações que envolvem as demais personagens acerca da veracidade e dos improváveis desdobramentos do fato. O cenário urbano provinciano, caracterizado pelo esquecimento e abandono a que estão submetidos seus habitantes, denota um contexto de alienação que simboliza no plano do microcosmo um ambiente social segregado e distanciado da realidade nacional, representando esta um macrocosmo conturbado por uma ditadura envelhecida. A seguir, os fragmentos que comprovam tal assertiva:

Em Vilamaninhos as pessoas já não podem encarar o nascer do dia como antes, porque suspeitam que há um ser desconhecido entre as casas. Tanto pode estar a apodrecer dentro do poço, como a reproduzir-se em cima de uma varanda. Ou nos escombros dos muros. Assim, quando sobem as ruas sozinhas, batem os calcanhares, 
como nunca haviam batido, para afugentar o medo. Se carregam as compras, acompanhadas, falam baixinho segredos de orelha a orelha. (JoRGE, 1980: p. 37)

Na verdade, a pleno meio da estrada avançava um carro singular, porque vinha pejado de soldados garbosos e épicos, penetrando já pelo centro de Vilamaninhos com bandeiras e flores. E cantavam por um altifalante como se viessem munidos de uma poderosa orquestra. Agora já o espetáculo era tão real e tão bonito que todos. Esquecidos desses primeiros segundos de pasmo e confusão. Sentiram estar suspenso o toque, o canto e a audição desde há muito. Para só ouvirem e verem aquilo que chegava em cima dum carro aberto e blindado. Todos tinham a certeza que desde o tempo dos reis nunca mais se vira de igual. (JorGe, 1980: p. 152-153)

O Dia dos Prodígios encena, num ambiente de hinterlândia, os impasses de uma ordem social sufocante que aprisiona e cerceia a liberdade de indivíduos caracterizados pela segregação e alienação. O espaço da pequena cidade enclausura seres marcados por uma violência muitas vezes simbólica, mas que alegoriza, no pequeno mundo de um lugarejo distante, perdido e esquecido no tempo, um vasto mundo que pode representar uma nação inteira oprimida por um regime autoritário implacável.

Lídia Jorge concentra-se no episódio formidável de uma cobra voadora que abala a monotonia de uma pequena comunidade algarvia, predispondo pessoas, até ali acomodadas à rotina de opressão e exclusão, ao desejo de transformação, mais interior que exterior, como parece sugerir a narrativa (por que mais profunda e significativa?), numa evidente correlação com o episódio histórico da Revolução dos Cravos de 25 de Abril de 1974, um acontecimento que propiciou modificações decisivas na sociedade lusitana com desdobramentos perceptíveis ainda na atualidade.

Como ato de resistência, vale sublinhar, a escrita do referido romance indicia certos impasses de uma nação sufocada por um regime político truculento. Lídia Jorge retrata a procura talvez desinteressada versus a euforia enganosa referente a um tempo de formidáveis mudanças, após uma época histórica de letargia inibidora, assinalando-se o desencontro entre o anseio e a efetiva transformação, entre a promessa e a concretização do gesto, de maneira a ressaltar a distância reconhecidamente enorme entre a liberdade vislumbrada em tempo de abertura e a dificuldade de ativação dos meios eficazes da ação transformadora.

Para concluir, vale reafirmar que o romance de Lídia Jorge faz parte de uma nova conjuntura estética, cultural e ideológica inaugurada pela ficção portuguesa pós-25 de Abril, descrita da seguinte maneira pelo consagrado crítico Carlos Reis:

Em termos mais específicos (e ainda assim inevitavelmente sintéticos) deve dizer-se que a Revolução de 25 de Abril de 1974 pôs termo a um tempo político e cultural algo incaracterístico. Esse tempo vem a ser a etapa final e a vários títulos agônica de um regime ditatorial, repressivo e isolacionista, com tudo o que isso significou de 
limitação à livre expressão do pensamento e das práticas artísticas e com os efeitos que em parte observamos em relação ao Neo-realismo e a movimentos literários afins. Por outro lado, a abertura política trouxe consigo conseqüências diversas, quase sempre constituindo um potencial de tematização literária que a ficção muitas vezes acolheu: a liberdade de expressão e a descolonização permitiram rever ficcionalmente os dramas individuais e coletivos da guerra colonial; paralelamente foi tomando corpo uma cada vez mais evidente consciência post-colonial; do mesmo modo, o redesenho das fronteiras nacionais estimulou uma reflexão identitária (incluindo-se nela a velha questão da relação com a Europa) a que a literatura, naturalmente, não ficou alheia. (ReIs, 2005: p. 287)

$\mathrm{Na}$ exposição acima da configuração do contexto histórico e cultural do período pós-25 de Abril de 1974, movimento do qual faz parte o mencionado romance de Lídia Jorge, é importante reforçar que a referida obra, ao representar alegoricamente o desaparecimento de um regime ditatorial esclerosado, acaba por vislumbrar, de modo altamente irônico, diga-se de passagem, os titubeios de uma abertura política caracterizada por alguma incerteza e pela natural propensão a todas as formas de riscos. O certo é que, por construir personagens que circulam em espaços que conotam uma reiterada atmosfera de cerceamento, O Dia dos Prodígios repercute, com grande domínio técnico da narrativa e efetiva realização artística do romance, a atmosfera de intenso autoritarismo que a literatura de ênfase social em língua portuguesa condenou de forma recorrente, ao longo do século $\mathrm{xx}$, numa representação contundente de um regime de força que afetou todos os âmbitos da sociedade portuguesa durante boa parte da última centúria, por meio de uma ditadura renitente em Portugal, que insistia em permanecer indefinidamente. Nem toda espera é essencialmente sebastianista e o sonhado e desejado 25 de Abril transformou-se historicamente no dia da liberdade, extraordinário e triunfante, como um dia de festa prometido e afinal cumprido. Entretanto, é conveniente perguntar: foi um dia realmente prodigioso? O romance de Lídia Jorge, graças ao sentido ambíguo que permanece como tensão estética e ideológica, não parece ser tão taxativo assim.

Resumo: $\mathrm{O}$ trabalho analisa o romance O Dia dos Prodígios, da escritora portuguesa Lídia Jorge (1946), com uma abordagem que enfoca a relação literatura e autoritarismo, por meio do estudo de personagens e do espaço.

Palavras-chave: Literatura; autoritarismo; José J. Veiga; Lídia Jorge.

\begin{abstract}
The work analyzes the novels O Dia dos Prodígios, by portuguese writer Lídia Jorge (1946), an approach that focuses on the relationship between authoritarianism and literature, through the study of characters and space.
\end{abstract}

Keywords: Literature; authoritarianism; Lidia Jorge's novel, O Dia dos Prodígios. 
REFERÊNCIAS BIBLIOGRÁFICAS:

Abdala JR., Benjamin. Literatura, História e Política, 2. ${ }^{a}$ ed. São Paulo: Ateliê Editorial, 2007. CAndido, Antonio e outros. A Personagem de Ficção. São Paulo: Perspectiva, 1974.

Ginzburg, Jaime; Umbach, Rosani Ketzer. Literatura e Autoritarismo. In: Cosson, Rildo (org.). 2000 Palavras: as Vozes das Letras. Pelotas, RS: PPG-Letras, UFPEL, 2000, pp. 237-242.

Jorge, Lídia. O Dia dos Prodígios. Lisboa: Europa-América, 1980.

Lins, Osman. Lima Barreto e o Espaço Romanesco. São Paulo: Ática, 1976.

ReIs, Carlos. História Crítica da Literatura Portuguesa. Do neo-realismo ao post-modernismo. Lisboa: Verbo, 2005, vol. IX.

Tutikian, Jane. Inquietos Olhares. São Paulo: Arte \& Ciência, 1999. 
